\title{
Online measuring the electrical resistivity of molten nugget of stainless steel in resistance spot welding
}

\author{
Kang Zhou ${ }^{\mathrm{a}}$, Tuo Shi ${ }^{\mathrm{b}}$, Lilong Cai ${ }^{\mathrm{b}, *}$ \\ a State Key Laboratory of High-Temperature Gas Dynamics, Institute of Mechanics, Chinese Academy of Sciences, Beijing, China \\ ${ }^{\mathrm{b}}$ Department of Mechanical and Aerospace Engineering, Hong Kong University of Science and Technology, Hong Kong SAR, China
}

\section{A R T I C L E I N F O}

\section{Article history:}

Received 26 April 2017

Received in revised form 18 May 2017

Accepted 29 May 2017

Available online 7 June 2017

\section{Keywords:}

Electrical resistivity

Resistance spot welding

Solid metal

Molten nugget

\begin{abstract}
A B S T R A C T
The variation characteristics of electrical resistivity of the parent metal can improve in-depth understanding of the resistance spot welding (RSW) process. According to the characteristic of RSW process and the physical principle of electrical resistivity, a comprehensive mathematical description of the electrical resistivity measurement of the molten nugget can be obtained. Then a series of corresponding experiments, including the RSW operation to obtain the dynamic resistance, online temperature measurement to obtain the electrical resistivity of solid metals and metallurgical analyses to obtain the size of the molten nugget, were sequentially conducted. The results of the electrical resistivity of the molten nugget can be obtained according to relative measurements, calculations and analyses. The work can benefit the establishment of accurate mathematical model for RSW process, and then serve the welding automation, corresponding researches and actual production process.
\end{abstract}

(c) 2017 The Society of Manufacturing Engineers. Published by Elsevier Ltd. All rights reserved.

\section{Introduction}

Resistance spot welding (RSW) is a commonly employed sheet metal joining technology, and extensively used for joining steel components with bodies and frames of automobiles, trucks, trailers, buses, recreational vehicles, and railroad passenger cars, as well as office furniture, appliances, and many other products [1-4]. However, during the process, there are a lot of uncertainties and disturbances, such as surface roughness or caps from electrode cap, contaminations, poor fit-up condition, thickness and/or stack-up variation of the parent metal sheets for welding operation [5-8]. Even for the parent metal sheets from the same batch, the variation of the weld quality may be very large, under the condition that an ideal preliminary welding schedule has been provided.

Currently, assuring weld quality and improving the heat efficiency are very crucial both in academic researches and practices during the industrial production. However, the process is very complicated and involves interactions between electromagnetic, thermal, mechanical, fluid, metallurgical fields, so that the parent metals undergo a multi-field coupled environment. In addition, the nugget formation and growth involves a lot of process variables [9]. To ensure the weld quality, many scholars and experts

\footnotetext{
* Corresponding author.

E-mail address: melcai@ust.hk (L.Cai).
}

employed a lot of process signals and relative mathematical tools to establish the models for online monitoring and controlling the weld quality. In general, dynamic resistance and electrode signal are two the most commonly used process variables, not only to online evaluate the weld quality [5,10-13], but also to comprehensively analyze and understand the welding process [14-17]. Also, various sensors may be employed together to achieve the goal $[18,19]$. Though these works can obtain satisfactory results under individual situation, the effects were relative to the specific experimental environments and analysis tools, in other words, the works lacked of enough generality and could only be employed in limited occasions.

To develop a more general method to improve the welding production, the internal physical variations must be clearly understood. Establishing the corresponding models were also be employed by many scholars and researchers, such as employing finite element method (FEM) to establish the models for predicting the temperature distribution and spot nugget size in a spot welded steel joint [20], monitoring the impact of the process variables on the final products [21], analyzing the features of nugget formation and growth [22,23], or doing failure analysis [24]. However, the governing differential equations cannot accurately predict the heat transfer phenomena if phase changes are involved, some important parameters, such as electrical resistivity, thermal conductivity, specific heat, density, and thermal diffusivity, which are required to precisely compute the temperature distribution, are not 
available in current situation. In addition, in these numerical conclusions, many assumptions must be used. It seriously obstruct the achievement which can improve the quality of welding products. Moreover, some previous works which may concern the measurement of the thermodynamic characteristics of the metals [25], however, the works involves some complex measuring system and mathematical structures and may not be able to repeatedly realize in other occasions during the RSW process. Currently, the accurate values of those characteristics parameters obtained from actual welding operations are required to serve the academic researches or industrial production.

Because these parameters which are used in model establishment are mutually relative, if one parameter can be precisely explored, others can be induced. However, during the RSW process, it is difficulty to employ precise instruments to measure these physical parameters in real time, due to the physical change occurred inside of the parent metals, and the duration is very short, as well as the measurement is easily affected by experimental environments. Hence, recently there are few work concerning how to obtain these important parameters. Among these parameters, electrical resistivity of the parent metal can directly reflect the metal internal variation during the different stages of the process, and the electrical resistivity has a simple mathematical description related to the resistance of the parent metals and the nugget size, which can be obtained from actual welding experiments, so that it can be employed to be firstly explored, and then as an important reference and foundation to induce other parameters.

In this work, a theoretical and experimental method is proposed to online measure the electrical resistivity of the parent metal sheets during the RSW process. The measurement is based on the principles of electrical resistivity and RSW process, and combines the accurate online monitoring tools and algorithms. In Section 2, the principle of the RSW and the proposed method will be clearly illustrated. Section 3 will provide the experimental procedures and results. Section 4 will supply the detailed calculating results and relative discussions. Finally, some concluding remarks and suggestions for the future works will be offered in Section 5 .

\section{Principle of the RSW and proposed method for measuring the electrical resistivity}

During the process of RSW, the parent metal sheets absorb energy and then melt. No matter in large scale RSW or small scale RSW, Joule heat is essential to join the original separated metal sheets [26,27], it follows the equation [1,28,29]:

$E=\int_{T_{1}}^{T_{2}} I(t)^{2} R(t) d t$.

where $E$ is the amount of Joule heat absorbed during the process, $I(t)$ is the welding current, $R(t)$ is the dynamic resistance of the parent metals, $T_{1}$ and $T_{2}$ are respectively the beginning and terminate of the energy delivery. During the process, the parent metals undergo the phase changing, which can be clearly understood by dynamic resistance profile, as stated in previous works $[30,31]$. At the beginning of the process, the dynamic resistance is composed of the contact resistance and bulk resistance, and the contact resistance dominates the whole value because the surface contaminants such as oxides and greases between sheet metals play a significant role [32]. As more and more Joule heat entering into the system, the contaminants collapse and the contact resistance shapely decreases, and then the bulk resistance dominated from this time on. At the same while the bulk resistance increases because the temperature is increasing. The temperature increases can induce phase change occurring, and then the amount of solid

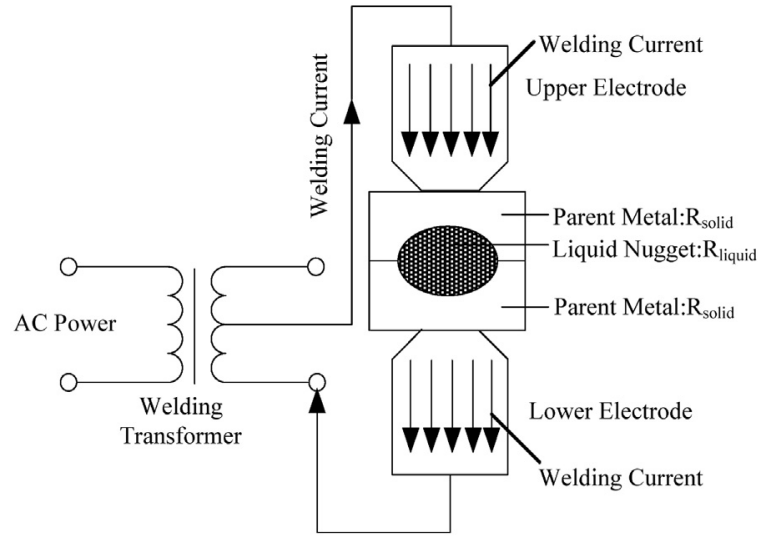

Fig. 1. Schematic figure of RSW.

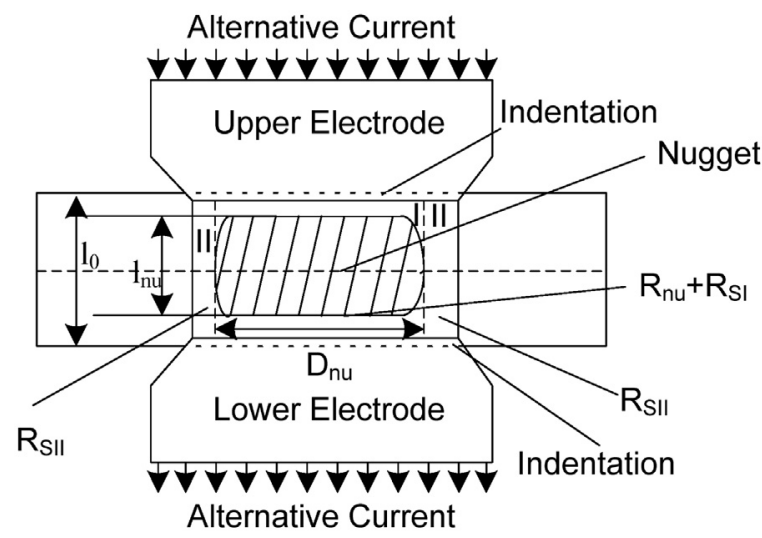

Fig. 2. The calculation variables during the RSW process.

metals decreases and the amount of molten metal increases, which can induce significant variations of dynamic resistance and other relative physical phenomena. As the welding current going through the electrodes may be not even distributed, the nugget may be not evenly formed. However, by means of the electrode force, this phenomenon may disappear within a short while. Hence, it can be assumed that the nugget may evenly be formed and grown during the process. Then the volume of the molten nugget can increase as the energy delivering into the system. When the molten nugget achieves the preliminary size by means of different observation methods, the delivery of external energy terminates, and then the molten nugget solidifies and original separated metal sheets can be combined together.

According to the principle of the RSW process, dynamic resistance can intuitively and compressively reflect the internal variation of parent metals during the process. Because the phase change processes are the main stages in this research, the beginning of the process, when the contact resistance dominates the whole dynamic resistance and the phase changes were very tiny, can be ignored, and then during the metal melting stage, the effect of the contact resistance is very low $[5,30,33,34]$. Hence, it is consumed that the dynamic resistance equals to the bulk resistance in the following works. Based on this principle, the schematic figure of the RSW can be depicted in Fig. 1.

It can be observed that when the phase change occurs, the total dynamic resistance between two electrodes is a mixture of resistances of solid metal and liquid metal, both of series connect and parallel connecting exist, according to the amount variation of two states of metals. To conveniently analyze the process, some special variables can be defined in Fig. 2 . 
In Fig. 2, the parent metal sheets which welding current goes through is divided into two parts: Part I and Part II. The width of Part I is equal to the diameter of the molten nugget, and it includes the molten nugget and solid metal. Part II only includes the solid metal and no phase change occurring, in other words, no molten nugget exists in this part. $D_{n u}$ is the nugget diameter, which is commonly employed to evaluate the weld quality [19,35], while $l_{n u}$ is the height of the nugget, both of these two parameter can determine the whole volume of the molten nugget. In addition, $l_{0}$ is the height of two parent metal sheets, $R_{S I}$ and $R_{\text {SII }}$ respectively denote the resistances of solid metal in Part I and Part II, while $R_{n u}$ is the resistance of the molten nugget. It can be obviously noticed that the resistance in Part I is a sum of solid metal resistance $R_{S I}$ and molten nugget resistance $R_{n u}$. Also, there are two indentations in the upper and lower surfaces of the parent metal sheets because of the electrode force squeezes the parent metals, and at the same time the phase change occurs. In this work, because the austenitic stainless steel was employed and the actual indentations were very small in reality, the effect of the indentation was ignored in the following analyses and calculations.

According to the previous contributions [36,37], the final shape of the molten nugget is approximately a cylinder. It can be seen from Fig. 2 that the total dynamic resistance between two electrodes is not just the simply sum of the constituent parts. It includes the series connection and parallel connection in reality. In this work, the proposed model combines these two types of connections, which is believed to reflect a more realistic scenario of the RSW. In Part I, the solid metal resistance $R_{S I}$ and molten nugget resistance $R_{n u}$ are in series connection, while the resistance in Part I and resistance in Part II are in parallel connection. According to the principle of resistivity calculation, following equations can mathematically describe the phenomena:

$\frac{1}{R_{t}}=\frac{1}{R_{s I I}}+\frac{1}{R_{s I I}+R_{n u}}$.

where $R_{t}$ is the total dynamic resistance, and then:

$R_{\text {SII }}=\rho_{\text {SII }} l_{0} /\left(A_{c}-A_{n u}\right)$,

$R_{S I}=\rho_{S I}\left(l_{0}-l_{n u}\right) / A_{n u}$,

$R_{n u}=\rho_{n u} l_{n u} / A_{n u}$

$A_{n u}=\pi\left(D_{n u} / 2\right)^{2}$,

where $\rho_{\text {SII }}, \rho_{S I}$ and $\rho_{n u}$ respectively denote the electrical resistivity of $R_{s I I}, R_{S I}$ and $R_{n u}$, and $A_{c}$ is the cross-section of the current,which is approximately the same as the cross-section of the electrode, as well as the $A_{n u}$ denotes the cross-section of the molten nugget. Then by combining Eqs. (2) and (3a)-(3c), the resistivity of molten nugget can be calculated as follows:

$\rho_{n u}=\rho_{s I I} R_{t} 1_{0} A_{n u} /\left[\rho_{s I I} 1_{0} A_{n u}-R_{t} 1_{n u}\left(A_{c}-A_{n u}\right)\right]-\rho_{s I}\left(l_{0} / l_{n u}-1\right)$.

Eq. (4) is the solution of electrical resistivity of the molten nugget. It is noticed that this resistivity can be obtained as long as all of the relative coefficients are obtained beforehand. Hence, the measurement can be transformed into seeking the solution of total dynamic resistance $(R t)$, the electrical resistivity of solid metals in Part I $\left(\rho_{\text {SI }}\right)$ and Part II $\left(\rho_{s I I}\right)$, the nugget diameter $\left(D_{n u}\right)$ and the penetration depth $\left(l_{n u}\right)$. To obtain these values, some experiments and sophisticated online measurements should be employed in following work.
Table 1

Chemical composition (\% by mass) of the parent metal used in the experiments

\begin{tabular}{lllllll}
\hline $\mathrm{C}$ & $\mathrm{Si}$ & $\mathrm{Mn}$ & $\mathrm{P}$ & $\mathrm{S}$ & $\mathrm{Cr}$ & $\mathrm{Ni}$ \\
\hline 0.08 & 1.00 & 2.00 & 0.045 & 0.030 & $18.0-20.0$ & $8.0-11.0$ \\
\hline
\end{tabular}

\section{Experiments}

\subsection{RSW operation}

Actual RSW experiments should be conducted to complete the measurements of above parameters. In this work, A $63 \mathrm{kVA}$ single-phase AC RSW machine was used. The electrode force was determined by a pressure differential of the two air pressure gauges. Because the air pressure gauge is difficult to adjust in real time, the force is a constant during the whole experimental process. The electrode force was $5500 \mathrm{~N}$ in our experiments. The materials of parent metal sheet was standard 300 series austenitic stainless steel (type 304) with thickness of $1.5 \mathrm{~mm}$, whose chemical composition was shown in Table 1 [38].

They came from cold-rolling galvanized steel sheet originally, to reduce the influence of coating, the metal sheets were processed using fine abrasive paper before used in the experiments. The electrode material was copper alloy, and the geometry used in this work was truncated cone with a $160^{\circ}$ angle and $5 \mathrm{~mm}$ face diameter. After several trails, the constant welding current of $6 \mathrm{kA}$ was chosen in the work. In our previous work $[39,40]$, an accurate constant welding current during the RSW process was realized, the desired value of constant welding current used the root-meansquared(RMS) value in reality. All the data processing and control operations were implemented via a Digital Signal Processor (DSP) dsPIC6014, which was made by Microchip Technology Inc. The frequency of the AC power source was $50 \mathrm{~Hz}$, while the frequency of actual control operation was $100 \mathrm{~Hz}$. In this work, 23 times welding operation were conducted, each welding operation was conducted 18 control cycles, in other words, the total welding time is $180 \mathrm{~ms}$, and then only 6 resistances which presented the best consistency were chosen for later calculation of electrical resistivity of molten nugget.

Due to the dynamic resistance is composed of contact resistance and bulk resistance, and the contact resistance dominates the total dynamic resistance at the beginning of the welding process, and then as the temperature increasing, the molten nugget began to form and grow, the contact resistance has shapely decreased and the effect on the phase change was very small. In this work, to reduce the influence of contact resistance, the dynamic resistance was concerned after a short while. Moreover, to obtain accurate value of dynamic resistance, other measures were also took. Because the surface of tip of the electrodes is also a main source of contact resistance, before and after each experiment, the electrodes were carefully polished to decrease the effects. Also, the shape of molten nugget is approximately a uniform cylinder at the end of the welding process [23,36], it means that the dynamic resistances at the later time is more relative to the shape of the molten nugget, because their variations were more uniform than those in the beginning. According to these principles, only the dynamic resistances at the later time were considered to testify the consistency. In this work, all the dynamic resistance values were collected after the second control cycles, the effect of contact resistance can be neglected under this circumstance. Fig. 3a showed the selected total dynamic resistance curves, the resistances begins from $20 \mathrm{~ms}$, which meant that the dynamic resistances in the first two control cycles were neglected; while Fig. $3 \mathrm{~b}$ showed that the resistance values at the later time of the process, following the Joule heat calculating method, which is $Q=I^{2} R t$, it can be seen that the heat energy delivered can be limited from $0.84 \mathrm{~kJ}$ to $1.08 \mathrm{~kJ}$, which 


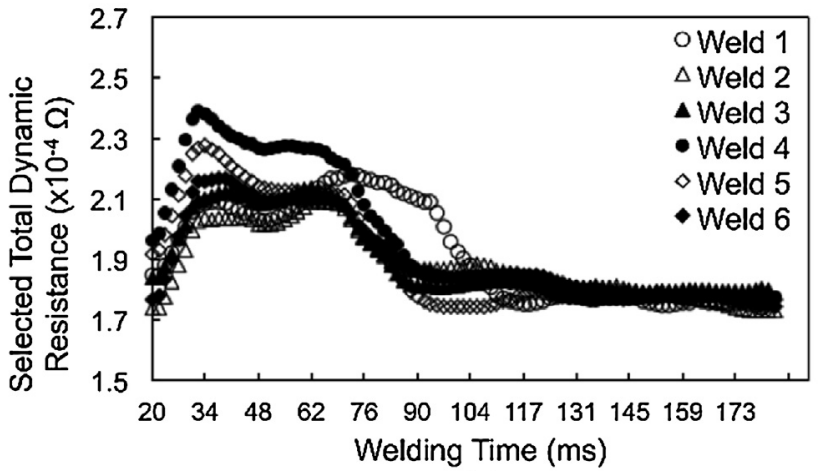

(a)

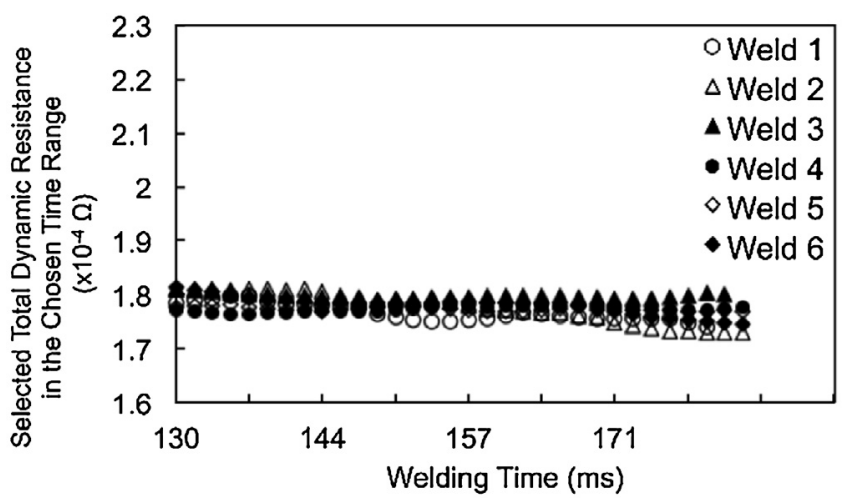

(b)

Fig. 3. (a) Collected integrated dynamic resistance of the selected 6 experiments; (b), The 6 dynamic resistance curves at the later time of the process.

denotes that the selected dynamic resistance has a satisfactory consistency. Moreover, the welding time in Fig. 3b was from $130 \mathrm{~ms}$ to $180 \mathrm{~ms}$, which denoted that the selected dynamic resistance values was chosen from 13th control cycle to 18th control cycle.

\subsection{Online temperature measurement}

The electrical resistivity of solid metal is closely relative to the temperature. To obtain the values of electrical resistivity of solid metal in Part I $\left(\rho_{\text {SI }}\right)$ and Part II $\left(\rho_{\text {SII }}\right)$, the temperature variation during the welding process should be collected beforehand. However, it is difficult to online measure the variation of temperature distribution, due to the welding duration is very short and the nugget formation and growth process is invisible [5,27], traditional sensors cannot be properly mounted and obtained reliable values [41]. In this work, the electrical resistivity of the solid state of the stainless steel can be extensively detected spanning across a broad temperature range. It can be calculated by inserting the measured temperature into a functional expression obtained from a curve fitting of the published resistivity [42], which is:

$\rho_{\text {SI }}=\rho_{\text {SII }}=0.2885 T^{0.2061}$.

In this work, given that all parts of the solid metal in the model shared the same current resource and possess a similar mechanism of heat loss, it was assumed that the temperature of the solid part of parent metal sheets was uniformly distributed during the process. Also, the electrical resistivity of the metal, which were $\rho_{s I}$ and $\rho_{\text {sII }}$, is assumed to be uniform. These two parameters were regarded the same in this work.

To obtain the temperature variation in real time, an infrared camera, which was FLIR Titanium Infrared Camera SC7700L, was employed to detect the temperature variation in this work. It can secure the detailed temperature variation of 12 spots evenly dis- tributed on the surface of the stack-up edge and electrode tip. The setup of the camera and the schematic of the temperature measurement are as shown in Fig. 4.

In the infrared camera, an emissivity of 0.2 was predefined and the FPS (frames per second) was set at 100. During the process, to reduce the randomness and obtain more convinced data, three repeated experiments were conducted for each spot. Because direct temperature measurement for the internal of solid metal was very difficult, the mean value of the temperature at the 12 testing spots on the surface was adopted and assumed to represent the overall temperature of the solid metal. Fig. 5 showed the captured images of the welding area at different welding times.

According to the measurement results, it can be observed that shortly after the welding current of $6 \mathrm{kA}$ was applied, the temperature of the 12 testing spots had a precipitous change within a short time. The temperature of the spots kept at around the maximum value for a while due to the current was maintained for a short time inducing maintained Joule heat. It was observed that despite that the testing spots exhibited distinct temperature variation tendencies, consistent sharply increasing from room temperature to the maximum were detected within the approximately the same intervals, which was about 5 frames. Consequently, the average rate of the temperature increasing for all the spots can be calculated according to above information. After seriously analysis and calculation, the average rate of temperature rise for the solid metal, which can be mathematically described as $\Delta T_{\text {average, }}$ was around $2.7^{\circ} \mathrm{C} / \mathrm{ms}$.

Though there are latent heat and heat energy loss existed in the system, their effects cannot achieve $10 \%$ after comprehensive analysis. Then according to above analysis, under this specific welding conditions and environment, the temperature of the solid metal at any specific time when the welding current goes through the parent metal sheets and the welding action is in heating stage can be correspondingly calculated. For example, if the welding time is $180 \mathrm{~ms}$, the corresponding temperature of the solid metal is about $2.7^{\circ} \mathrm{C} / \mathrm{ms} \times 180 \mathrm{~ms}=486^{\circ} \mathrm{C}$. In addition, the cooling stage of the welding process was not concerned in this work because it was irrelative to the measurement of the electrical resistivity of molten nugget.

\subsection{Metallographic experiments and analyses}

In previous parts, the electrical resistivity of the solid metal can be obtained, and then the metallographic experiments were conducted to explore the size of the molten nugget. The nugget size refers to the nugget diameter and its penetration depth, which were $D_{n u}$ and $l_{n u}$, respectively. The nugget size can be obtained by destructive test after each experiment. To obtain precise and reliable information of nugget size, after cutting off the weld using a low speed diamond wheel saw, the specimen was mounted using a cold mounting method with a polymer resin to cast a mold, and then it was ground and polished carefully to obtain a smooth surface. Then after chemical corrosive was used, the heat-affected zone (HAZ) can be clearly shown [43], which can be precisely measured by optimal microscope. Fig. 6 shows the surface of a weld crosssection after grinding and polishing.

After obtaining the $D_{n u}$ and $l_{n u}$ of each weld, its correlation to the heat delivery can be presented based on the previous studies showing that in all cases, molten nugget can increase if the welding current continues going through the parent metal sheets, under the normal welding conditions [5,37].

Under each level of welding current, three welds were produced following three times measurement so as to reduce the random errors. Fig. 7 shows the measured nugget size as a function of heat delivery. The welds were produced under welding currents from $3.75 \mathrm{kA}$ to $6 \mathrm{kA}$ with an interval of $0.25 \mathrm{kA}$. 

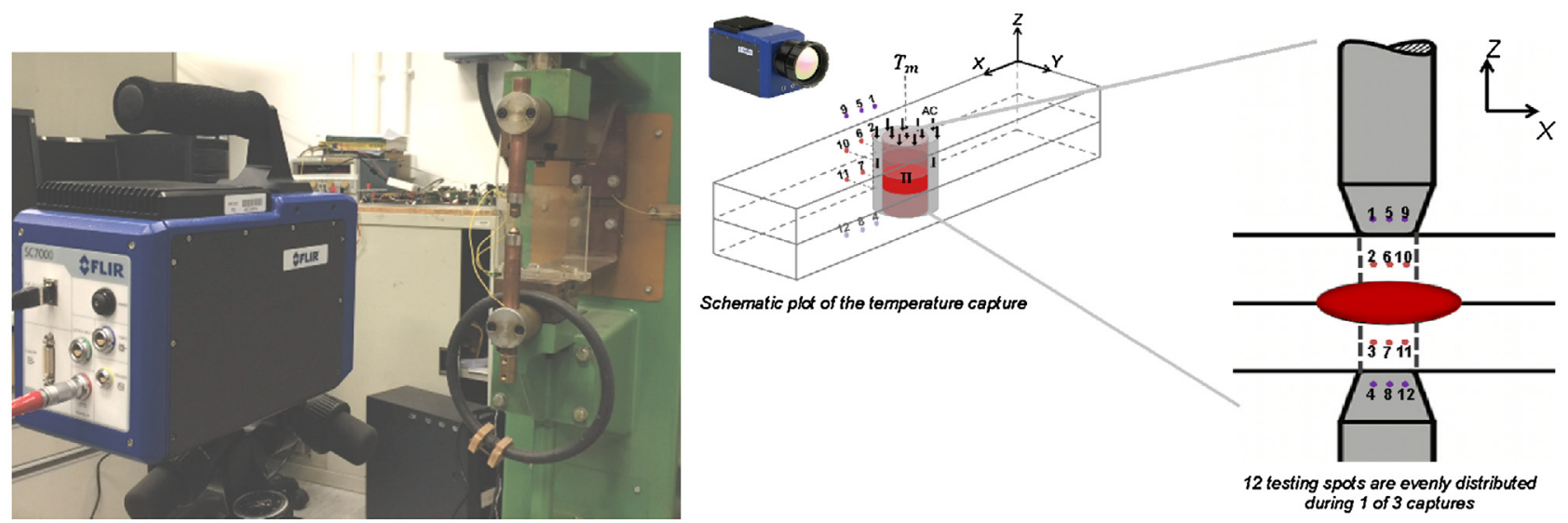

Fig. 4. Setup of the infrared camera and the schematic of the temperature Measurement.

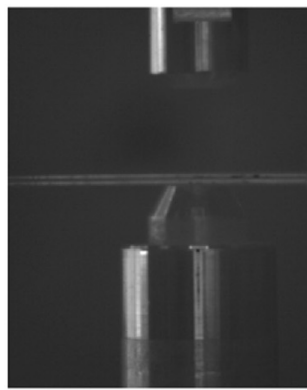

$t=0.85 \mathrm{~s}$

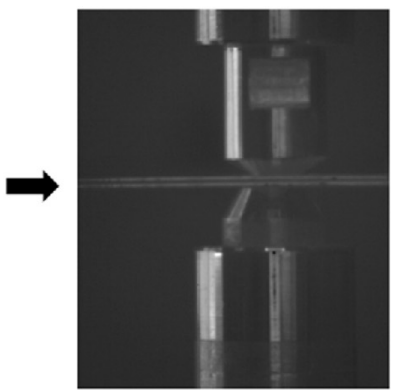

$t=1.11 \mathrm{~s}$

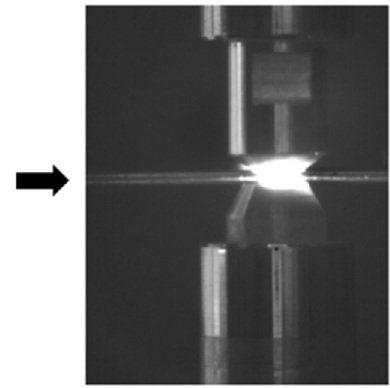

$t=1.32 \mathrm{~s}$

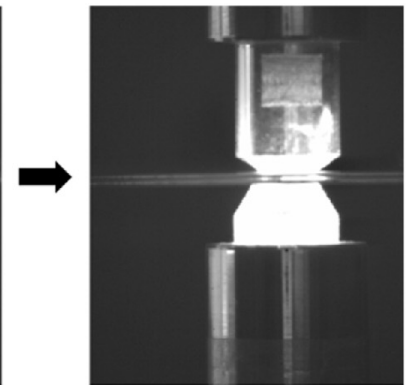

$t=1.4 \mathrm{~s}$

Fig. 5. Captured images by the infrared camera at different welding times.

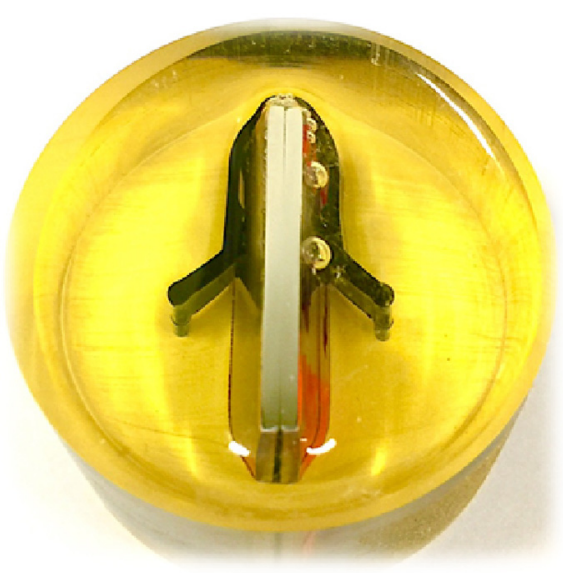

Fig. 6. The surface of a weld cross-section after grinding and polishing processes.

According to our previous contributions, the measured nugget size was found to have an approximate relation to the cubic root of the heat delivery into the system [36]. Specific mathematical expression of the relations are shown in following equations:

$D_{n u}(t)=\beta(t) E(t)^{1 / 3}$

$l_{n u}(t)=\alpha(t) E(t)^{1 / 3}$

where $E(t)$ was the heat energy delivery into the parent metal sheets, and $\alpha(t)$ and $\beta(t)$ were the calibration coefficients for $D_{n u}$ and $l_{n u}$. For each weld, the calibration coefficients can be solved by calculation of heat energy delivery and measuring nugget diameter and penetration depth offline. Fig. 8 shows the solved calibration coefficients of the selected welds.

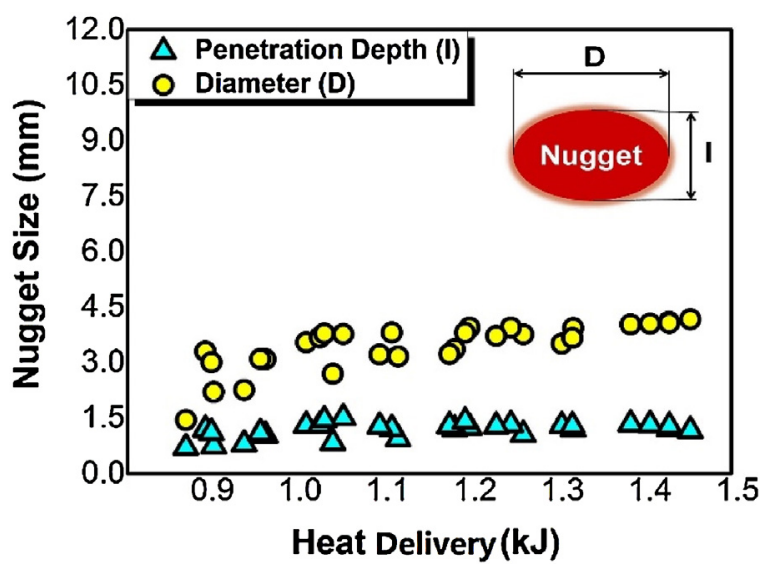

Fig. 7. Measured nugget size as a function of heat input. Both of the nugget penetration depth and diameter were measured under the room temperature.

Curve fitting was employed to obtain proper functions to describe the relation. Then the mathematical equations can be shown as follows:

$D_{n u}(t)=[0.4809 \mathrm{E}(t)+3.8318] E(t)^{1 / 3}$

$l_{n u}(t)=[0.1744 \mathrm{E}(t)+0.9239] E(t)^{1 / 3}$

Illustrated by Figs. 7 and 8 and Eqs. (7a)-(7b), both of the nugget diameter and penetration depth were found to increase almost linearly versus increased heat delivery within the selected timescale, and the magnitude of the diameter constantly exceeded the penetration depth, presumably the cause of inducing the approximate cylinder-like shape of the molten nugget. 


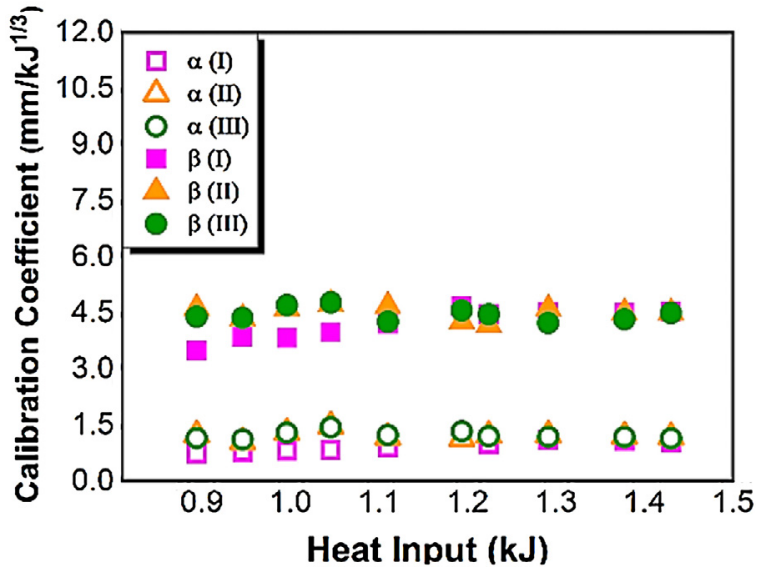

Fig. 8. The calibration coefficients of the function of heat input. I, II, and III represent 3 computations based on 3 repeated measurements.

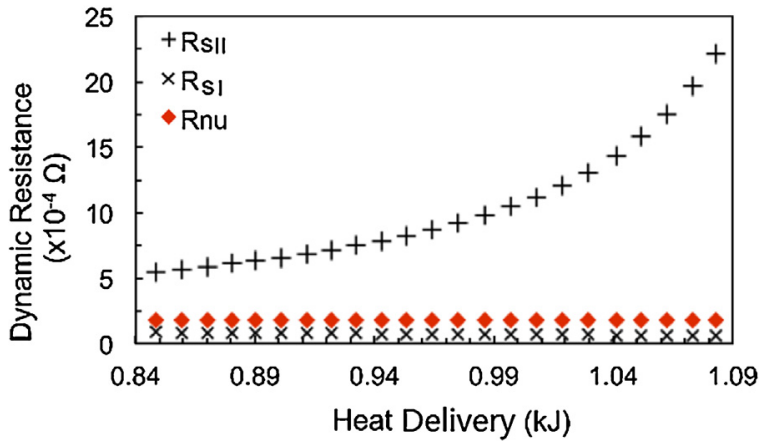

Fig. 9. Dynamic resistance of the molten nugget compared to resistance of solid metal in two parts.

\section{Calculation and corresponding discussion}

\subsection{Resistance of the molten nugget}

Referring to the Eq. (2), the resistance of the molten nugget could be written as follows:

$R_{n u}=R_{t} R_{S I I} /\left(R_{s I I}-R_{t}\right)-R_{\text {SII }}$

According to above illustrations, $R_{n u}$ can be obtained if dynamic resistance $R_{t}$, the resistance of solid metal in Part I and Part II, which were $R_{S I}$ and $R_{S I I}$ were given. To reduce the experimental randomness and improve the reliability of the calculation, above three resistances were the average of their original collected values. Then the solved dynamic resistance of the molten nugget was shown in Fig. 9, with its magnitude compared to both of $R_{S I}$ and $R_{S I I}$.

Since $R_{S I}$ was much larger than $R_{n u}$ and $R_{S I I}$, Fig. 10 showed the comparison between $R_{n u}$ and $R_{S I}$ to obtain better clarity.

According to Figs. 9 and 10, the resistance of solid metal in Part II was much larger than that in Part I. which may indirectly reflect the heat propagation phenomenon. Larger heat was delivered into the system, the higher temperature of the solid metal, which induces larger value of the resistances. Compared to the resistance in Part II, the resistances in Part I had no significant changes as the heat energy increasing, it will be clearly understood after the electrical resistivity would be obtained.

\subsection{Electrical resistivity of the molten nugget}

When the resistances of solid metal and molten nugget in Part I had been divided, the electrical resistivity of the molten nugget

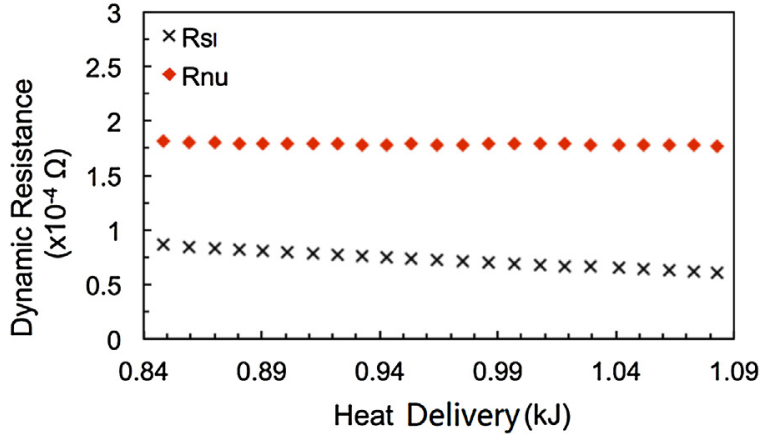

Fig. 10. Dynamic resistance of the molten nugget compared to resistance of solid metal in Part I.

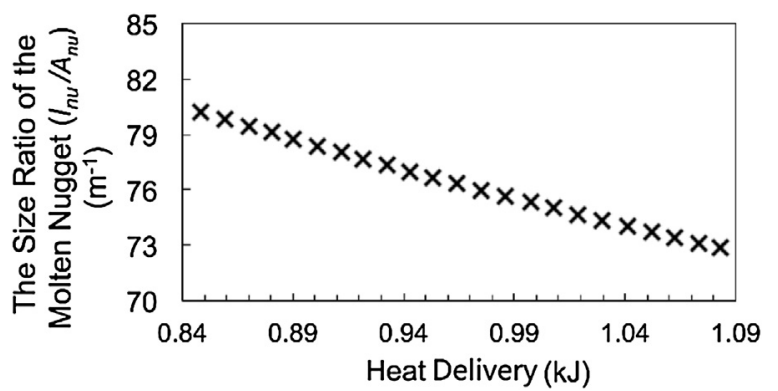

Fig. 11. The size ratio $\left(l_{n u} / A_{n u}\right)$ of the molten nugget as a function of heat input.

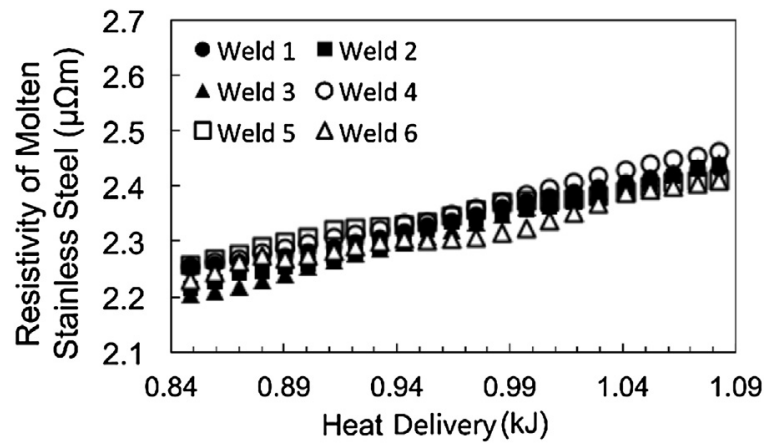

Fig. 12. Resistivity of molten nugget versus heat delivery. The cross-sectional area of the current was assumed to occupy $85 \%$ of the electrode tip area.

could be correspondingly calculated. After the molten nugget appeared and its growth process entered into a stable state, the resistance of molten nugget kept being larger than that of solid metal, so that more Joule heat was produced leading melting to propagate in order to increase the size of the molten nugget. Therefore, $R_{n u}$ was constantly larger than the $R_{S I}$, as shown in Fig. 10. It can be illustrated by means of the size ratio of the nugget. To give a clear illustration, the size ratio of the nugget, which is $l_{n u} / A_{n u}$ can also be shown in Fig. 11.

It can be seen that the size ratio of the molten nugget decreased as the heat delivery increased. This decreased tendency could be attributed to the cross-sectional area of the nugget extending faster than that of penetration depth during the process. Then the electrical resistivity of the molten nugget can be solved by Eq. (3), with all of the coefficients known at this stage. Fig. 12 showed the electrical resistivity of molten nugget versus heat delivery.

According to Fig. 12, 6 curves of the electrical resistivity of the molten nugget exhibited a constant increased tendency. From averaged minimum of $2.20 \mu \mathrm{Wm}$ under the heat delivery of $0.84 \mathrm{~kJ}$, to the averaged maximum of $2.46 \mu \Omega \mathrm{m}$ under the heat delivery of $1.09 \mathrm{~kJ}$. 
Due to the temperature of the molten nugget cannot be measured, the electrical resistivity versus temperature cannot be shown under the current circumstance. However, electrical resistivity is much sensitive to the temperature variation. It can assumed that temperature was increasing as the heat delivery increasing. In addition, according to Figs. 11 and 12 and Eq. (3c), the size ratio of the molten nugget $\left(l_{n u} / A_{n u}\right)$ and resistance of molten nugget $\left(R_{n u}\right)$ were decreased as the heat delivery increasing, however, the size ratio dropped much shapelier than that of resistance. It showed that crossing-sectional area was much relative to the variation of electrical resistivity during the process. This can explain the phenomenon shown in Fig. 11, which showed the resistance of molten nugget had no significant changes as the heat delivery increasing. In addition, as the heat delivery increasing, the electrical resistivity was increasing, it showed that for the molten nugget, the resistivity was also sensitive to the temperature variation.

\section{Calculation and future work}

In this work, the electrical resistivity of the molten nugget had been theoretically deduced and experimentally obtained, according to detailed theoretical analyses based on the principle of electrical resistivity and RSW process, experimental designs and corresponding calculations. The experimental designs included dynamic resistance measurement, online temperature measurement and metallurgical measurement, while the calculation was based on natural characteristics of electrical resistivity and RSW process. To assure the accuracy of measurement and calculation, all of the measurements and calculations employed the averaged value of at least 3 times' values. Due to the method in this work only employed the usual tools and simple mathematical calculations, without other complex relative tools, it was general and can be repeatable in other occasions, such as measuring the resistivity of other parent metals in reality, especially the light metals, the rare metals. We believe it will be useful in the welding area, not only in academic research, but also in actual industrial production.

In the future, the work can be a foundation of deducting the variations of other characteristic parameters, such as metal density, thermal conductivity, entropy, specific heat during the welding process. Then the detailed characteristic variation of the metal during the welding process can be obtained, and an accurate mathematical models can be established to serve the welding automation and establishment of integrated welding data library.

\section{Acknowledgments}

The project is supported by Natural Science Foundation of China (Grant No: 51605103) and Research Grants Council of Hong Kong SAR, China (Grant No: GRF610611).

\section{Reference:}

[1] Robert J, Messler W, Jou M. Review of control systems for resistance spot welding: past and current practices and emerging trends. Sci Technol Weld Join 1996;1:1-9.

[2] Zhou K, Cai L. Online measuring power factor in AC resistance spot welding. IEEE Trans Ind Electron 2014;61:575-82.

[3] Liu J, Xu G, Ren L, Qian Z, Ren L. Defect intelligent identification in resistance spot welding ultrasonic detection based on wavelet packet and neural network(online first). Int J Adv Manuf Technol 2016:1-8.

[4] Chen S, Sun T, Jiang X, Qi J, Zeng R. Online monitoring and evaluation of the weld quality of resistance spot welded titanium alloy. J Manuf Process 2016;23:183-91.

[5] Zhou K, Cai L. Online nugget diameter control system for resistance spot welding. Int J Adv Manuf Technol 2013;68:2571-88.

[6] Wen J, Wang CS, Xu GC, Zhang XQ. Real time monitoring weld quality of resistance spot welding for stainless steel. ISIJ Int 2009:49:553-6.

[7] Podržaj P, Jerman B, Simončič S. Poor fit-up condition in resistance spot welding. J Mater Process Technol 2016;230
[8] Mazur W, Kyriakopoulos A, Bott N, West D. Use of modified electrode caps for surface quality welds in resistance spot welding. J Manuf Process 2016;22:60-73.

[9] Cho Y, Rhee S. Experimental study of nugget formation in resistance spot welding. Weld J 2003;82:195s-201s.

[10] Wan X, Wang Y, Zhao D, Huang Y, Yin Z. Weld quality monitoring research in small scale resistance spot welding by dynamic resistance and neural network. Measurement 2017:2017:120-7.

[11] Wan X, Wang Y, Zhao D. Quality evaluation in small-scale resistance spot welding by electrode voltage recognition. Sci Technol Weld Join 2016;21:358-65.

[12] Simončič S, Podržaj P. Image-based electrode tip displacement in resistance spot welding. Meas Sci Technol 2012;23:1-7.

[13] Simončič S, Podržaj P. Resistance spot weld strength estimation based on electrode tip displacement/velocity curve obtained by image processing. Sci Technol Weld Join 2014:19:468-75

[14] Ighodaro OL-R, Biro E, Zhou YN. Study and applications of dynamic resistance profiles during resistance spot welding of coated hot-stamping steels(online first). Metall Mater Trans A 2016:1-14.

[15] Fan Q, Xu G, Gu X. Expulsion characterization of stainless steel resistance spot weldingbased on dynamic resistance signal. J Mater Process Technol 2016;236:235-40.

[16] Zhang Y, Chen G, Lin Z. Study on weld quality control of resistance spot welding using a neuro-fuzzy algorithm. Lect Notes Comput Sci 2004;3215:544-50.

[17] Lai X, Zhang X, Zhang Y, Chen G. Weld quality inspection based on online measured indentation from servo encoder in resistance spot welding. IEEE Trans Instrum Meas 2007;56:1501-5.

[18] Chien C-S, Kannatey-Asibu JE. Investigation of monitoring systems for resistance spot welding. Weld J 2002;81:195s-9s.

[19] Li W, Hu SJ, Ni J. On-line quality estimation in resistance spot welding. J Manuf Sci Eng 2000;122:511-2.

[20] Eisazadeha H, Hamedib M, Halvaeec A. New parametric study of nugget size in resistance spot welding process using finite element method. Mater Des 2010;31:149-57

[21] Chigurupati P, Chun BK, Bandar A, Wu WT. Finite element modeling of resistance spot welding process. Int J Mater Form 2010;3:991-4.

[22] Ho JE, Wei PS, Wu TH. Workpiece property effect on resistance spot welding, components. IEEE Trans Packag Manuf Technol 2012;2:925-34.

[23] Wei PS, Wu TH. Workpiece property effects on nugget microstructure determined by heat transfer and solidification rate during resistance spot welding. Int J Therm Sci 2014;86:421-9.

[24] Noh W, Kim W, Yang X, Kang M, Lee M-G, Chung K. Simple and effective failure analysis of dissimilar resistance spot welded advanced high strength steel sheets. Int J Mech Sci 2017;121:76-89.

[25] Boivineau M. Thermophysical properties of metals at very high temperatures obtained by dynamic heating techniques: recent advances. Int J Mater Prod Technol 2006:26:217-46.

[26] Tohmyoh H, Sunagawa T. A parameter governing the melting induced at the micrometer level in a dissimilar metal wire system by joule heating. J Appl Phys 2015;117:234901-6.

[27] Williams NT, Parker JD. Review of resistance spot welding of steel sheets part 1 modelling and control of weld nugget formation. Int Mater Rev 2004;49:45-75.

[28] Zhou K, Cai L. Study on effect of electrode force on resistance spot welding process. J Appl Phys 2014:116:1-7. pp. 084902.

[29] Podržaj P, Polajnar I, Diaci J, Kariz Z. Overview of resistance spot welding control. Sci Technol Weld Join 2008; 13:215-24.

[30] Dickinson DW, Franklin JE, Stanya A. Characterization of spot welding behavior by dynamic electrical parameter monitoring. Weld J 1980;59(June):170s-6s.

[31] Tan W, Zhou Y, Kerr HW, Lawson S. A study of dynamic resistance during small scale resistance spot welding of thin Ni sheets. J Phys D: Appl Phys 2004:37:1998-2008.

[32] Wang B, Lou M, Shen Q, Li YB, Zhang H. Shunting effect in resistance spot welding steels-part 1: experimental study. Weld J 2013;92:182s-9s.

[33] Hamedi M, Atashparva M. A review of electrical contact resistance modeling in resistance spot welding(online first). Weld World 2017:61:269-90.

[34] Kaars J, Mayr P, Koppe K. Generalized dynamic transition resistance in spot welding of aluminized 22MnB5. Mater Des 2016;106:139-45.

[35] Ouafi AE, Belanger R, Guillot M. Dynamic resistance based model for on-line resistance spot welding quality assessment. Mater Sci Forum 2012;06-709:2925-30.

[36] Zhou K, Cai L. On the development of nugget growth model for resistance spot welding. J Appl Phys 2014;115:1-12. pp. 164901.

[37] Hassanifard S, Feyzi M. Analytical solution of temperature distribution in resistance spot welding. J Mech Sci Technol 2015;29:777-84.

[38] ASTM and SAE-AMS standards and specifications for stainless steel. ASTM International; 2013

[39] Zhou K, Cai L. A nonlinear current control method for resistance spot welding. IEEE/ASME Trans Mechatron 2014;19:559-69.

[40] Zhou K, Yao P, Cai L. Constant current vs. constant power control in AC resistance spot welding. J Mater Process Technol 2015;233:299-304.

[41] Simončič S, Podržaj P. Resistance spot welding control based on the temperature measurement. Sci Technol Weld Join 2013;18:551-7.

[42] Rudnev V, Loveles D, Cook RL, Black M. Handbook of induction heating (manufacturing engineering and materials processing). CRC Press; 2002.

[43] Leng Y. Material characterization. John Wiley \&Sons (Asia) Pte Ltd.; 2008. 